Article

\title{
Influence of the Weld Joint Position on the Mechanical Stress Concentration in the Construction of the Alternative Skid Car System's Skid Chassis
}

\author{
Petr Jilek*(D), Jan Berg and Baurice Sylvain Sadjiep Tchuigwa
}

check for updates

Citation: Jilek, P.; Berg, J.; Tchuigwa, B.S.S. Influence of the Weld Joint Position on the Mechanical Stress Concentration in the Construction of the Alternative Skid Car System's Skid Chassis. Appl. Sci. 2022, 12, 397. https://doi.org/10.3390/app12010397

Academic Editor: Nicola Bosso

Received: 10 December 2021

Accepted: 29 December 2021

Published: 31 December 2021

Publisher's Note: MDPI stays neutral with regard to jurisdictional claims in published maps and institutional affiliations.

Copyright: (c) 2021 by the authors. Licensee MDPI, Basel, Switzerland. This article is an open access article distributed under the terms and conditions of the Creative Commons Attribution (CC BY) license (https:// creativecommons.org/licenses/by/ $4.0 /)$.

\author{
Department of Transport Means and Diagnostics, Faculty of Transport Engineering, University of Pardubice, \\ Studentská 95, 53210 Pardubice, Czech Republic; jan.berg@student.upce.cz (J.B.); \\ bauricesylvain.sadjieptchuigwa@student.upce.cz (B.S.S.T.) \\ * Correspondence: petr.jilek@upce.cz
}

\begin{abstract}
This paper deals with the optimization of the crossbars, parts of the existing frame of the experimental system of the Alternative SkidCar. This part plays a crucial role and is designed to enable and ensure reduced adhesion conditions between the vehicle and the road. To this end, its optimization targeted here is performed using both analytical calculations and simulations in MSC Adams software, wherein the loading forces and boundary conditions on the frame support wheels are obtained considering the static conditions, as well as the change of the direction of travel. The least favourable load observed was used, later on, as the input value for the strength analysis of the frame. The analysis was performed using the finite element method (FEM) in SolidWorks. Based on the linear and nonlinear analyses performed, the course of stress on the frame arms and critical points with the highest stress concentration were determined. Subsequently, according to the results obtained, a new design for the current frame was proposed and, thereby, warrants greater rigidity, stability and strength to the entire structure, while reducing its weight and maximizing the potential of the selected material. The benefit of the current contribution lies in the optimization of the current frame shape, in terms of the position of weld joints, the location of the reinforcements and the thickness of the material used.
\end{abstract}

Keywords: weld joint; car stability; weight; SkidCar; construction optimization

\section{Introduction}

The reduction in the number of road accidents and, in particular, their serious consequences is one of the European Union's key objectives for improving road safety, as set out in the EU Road Safety Policy Framework 2021-2030 document-Recommendations on Next Steps Towards "Vision Zero". We identify two ways to achieve this vision: either by improving the drivers' skills of car control or by improving road safety and cars' autonomy to utilize artificial intelligence (AI). Nevertheless, it is not excluded that the combination of the human factor (portrayed by the driver) and autonomous vehicles on real road traffic can be of great help in a condition that carries a significant risk of collision [1]. Therefore, it is necessary to develop new or to improve existing car control systems [2-8], with the help of both existing data, and the theories and tools at our disposal, and proceed with the verification and validation of results compared to those obtained experimentally in laboratory conditions. This applied approach results in a rapid development while maintaining financial efficiency, unlike in cases in which fundamental research requires substantial financial resources. However, before any system is put into real operation, it is worth recalling that it must pass a homologation process that is conditional on the satisfactory completion of the experimental tests. It is precisely the testing of prototypes under real conditions for car manufacturers that carries a great risk of damaging the vehicle, or there is a growing risk of espionage from competing manufacturers. Therefore, simulated conditions are 
increasingly used in prototype testing. This includes testing cars on skid surfaces [9-11]. The disadvantage of the sliding surfaces is that the adhesive force changes in step, either for all wheels or for the wheels on the same side of the car. As an alternative to surfaces with reduced adhesion, an additional frame can be used to supplement the car. These frames are delivered in the commercial sphere under the designation SkidCar (SC) [12]. The operating principle of the frame is as follows: with the help of two pairs of wheels, SC can transfer part of the weight of the vehicle through these wheels. In this way, a similar reduction in the adhesive force on the wheels [13] is achieved as on the skid surface. By using the variation in the adhesion force on any wheel, it is possible to simulate an oversteer skid, the asymmetry of the adhesion conditions with the longitudinal axis of the vehicle and other boundary situations that can occur in real operation compared to the sliding surfaces.

Since SkidCar is designed to teach drivers in the so-called anti-skid schools, it is designed as a solid and durable device wherein weight does not play a significant role.

The motivation of this work is to help SkidCar manufacturers to deliver a reliable frame for a given group of cars [14], which is, of course, significantly limited. Thereby, a prototype of an Alternative SkidCar (ASC) [15] has been compiled, with the advantage of possibly being used on an individual vehicle construction, that is to say, an experimental vehicle [16]. The frame has been designed to verify and confer the usability for vehicle stability. During the construction, the frame is made of commonly available materials with which the minimum construction cost is decisive. Since the alternative SkidCar proved very successful during the driving tests, it has been optimized.

This research improves the alternative SkidCar design used for the determination of the driving stability of the experimental car in experimental tests. The design and material optimization of the frame can provide an effective device for obtaining more accurate measurement data from experiments than the current design. The initial step of optimization is the design of the structure modification, for the sake of increasing the rigidity and reducing the weight of the frame as a whole. Since this is an added weight to the car, compared to its standard version, it is necessary to minimize this weight [16].

In terms of road safety, the stability of road vehicles is an important issue since it is related to several factors [17-19] that can be influenced, such as the appropriate steering and axle design, electronic car systems [20] and also the driver's abilities. The stability of the car can be assessed from many aspects [21], of which one of the options is the assessment of the change in the car's behaviour depending on the change in the adhesive force [22]. The change in the adhesion force between the wheels and the road can be achieved, step by step, by changing the coefficient of adhesion (skid surfaces) [23-27], or by a continuous change in the radial reaction of the vehicle wheels using the additional equipment: alternative SkidCar [13]. However, the requirement is that the incidence, due to the change of its behaviour as a result of the adhesive forced added to the vehicle, should be consistently low. For instance, in the present paper [15], an experimental measurement was carried out, where the behaviour of the car at a reduced adhesion force was determined using the alternative SkidCar system.

Furthermore, to improve the satisfaction of the results obtained, the optimization of the frame is investigated in the present paper. More precisely, the variable of the optimization to be solved is the reduction of the weight of the ASC as a whole, and increasing its rigidity at the same time. With the help of an optimized ASC, accurate results can be recorded from road vehicle stability testing, which corresponds to the vehicle's limit state when driving in winter, with different adhesion conditions on individual wheels. This condition cannot be achieved with the use of a sliding surface. When using the ASC frame, it is possible to monitor its behavior within the time on the car, in the form of the pitching and rolling rotation of the body [28], the yaw rate, longitudinal and transversal acceleration, the angle of the directional deviation at a defined driving speed and the given steering wheel rotation course [29]. The issue of testing the driving stability of cars in relation to the change of adhesion conditions, by using an additional frame mounted on the vehicle, is only marginally addressed in the current scientific area [30]. 


\section{Materials and Methods}

For the sake of carrying out experimental driving stability measurements on a passenger car, an alternative to the commercially available SkidCar was mounted on an individually built vehicle (the experimental car 4WS), in the Laboratory of the Faculty of Transport Engineering at the University of Pardubice.

With the help of ASC, it was possible to optionally change the radial reactions of the vehicle wheels and thus their adhesion [31]. The auxiliary wheels of the alternative SkidCar system were free to rotate around the vertical axis, so they did not lead the vehicle, but only transmitted vertical forces. The reduction of the adhesive force on the vehicle wheels was achieved through the reduction of the radial reaction of these wheels. The car was lightened by a hydraulic circuit controlling the vertical position of the ASC frame above the ground, thereby reducing the radial reactions of the vehicle wheels. For this reason, the vehicle could be brought to the limit of stability, i.e., to skid at a lower (safe) speed, even on dry asphalt. More detailed specifications and the use of ASC is processed in [14].

The ASC frame was attached to the body of the experimental vehicle through a screw connection. The front crossbar with the front wheel units was located behind the front axle axis, whereas the rear crossbar with wheel units was in front of the rear axle axis. The change in the wheels' radial reaction was set prior to the experimental measurement. The adjustment was performed by a hydraulic extension of the wheel unit. Detailed information on ASC is given in [13].

The current state of the ASC (Figure 1) consists of a steel demountable frame with material support, highlighted in Table 1. The frame comprises of two crossbars, two side members and four wheel units. The wheel units embody free-rotating rubber wheels, bearings, steel tubes and mechanical transmissions allowing the rubber wheels to be extended and retracted. Side members and wheel units are not subjected to optimization in this work. The frame is attached by a screw connection to the truss frame of the experimental vehicle. The side members are mounted on both sides of the car between the crossbars and increase the longitudinal stiffness of the ASC.

Table 1. Validation of the experimental measurement model.

\begin{tabular}{|c|c|c|c|c|c|c|}
\hline \multirow[b]{2}{*}{ k (-) } & \multicolumn{2}{|c|}{$\mathrm{Z}_{\mathrm{SCFL}}(\mathrm{N})$} & \multirow[t]{2}{*}{ Deviation (\%) } & \multicolumn{2}{|c|}{$\mathrm{Z}_{\text {SCFR }}(\mathrm{N})$} & \multirow[t]{2}{*}{ Deviation (\%) } \\
\hline & Experiment & Simulation & & Experiment & Simulation & \\
\hline 1.0 & 0.0 & 0.0 & 0.0 & 0.0 & 0.0 & 0.0 \\
\hline 0.8 & 848.0 & 834.0 & 1.7 & 839.0 & 831.0 & 0.9 \\
\hline 0.6 & 1696.0 & 1677.0 & 1.1 & 1677.0 & 1658.0 & 1.1 \\
\hline 0.4 & 2544.0 & 2516.0 & 1.1 & 2516.0 & 2498.0 & 0.7 \\
\hline 0.2 & 3393.0 & 3439.0 & 1.4 & 3354.0 & 3422.0 & 2.0 \\
\hline \multirow[t]{2}{*}{0.0} & 4241.0 & 4227.0 & 0.3 & 4193.0 & 4143.0 & 1.2 \\
\hline & \multicolumn{2}{|c|}{$\mathrm{Z}_{\mathrm{SCRL}}(\mathrm{N})$} & Deviation (\%) & \multicolumn{2}{|c|}{$\mathrm{Z}_{\mathrm{SCRR}}(\mathrm{N})$} & Deviation (\%) \\
\hline k (-) & Experiment & Simulation & & Experiment & Simulation & \\
\hline 1.0 & 0.0 & 0.0 & 0.0 & 0.0 & 0.0 & 0.0 \\
\hline 0.8 & 455.0 & 456.0 & 0.2 & 450.0 & 453.0 & 0.7 \\
\hline 0.6 & 910.0 & 956.0 & 5.0 & 900.0 & 937.0 & 4.1 \\
\hline 0.4 & 1365.0 & 1430.0 & 4.7 & 1350.0 & 1413.0 & 4.7 \\
\hline 0.2 & 1821.0 & 1872.0 & 2.8 & 1800.0 & 1855.0 & 3.1 \\
\hline 0.0 & 2276.0 & 2338.0 & 2.7 & 2250.0 & 2315.0 & 2.9 \\
\hline
\end{tabular}

Average deviation: $2.2 \%$; maximum deviation: 5.0\% $Z_{S C F L}$-radial reaction of the support front left wheel $(\mathrm{N})$ $Z_{S C F R}$-radial reaction of the support front right wheel $(\mathrm{N}) ; Z_{S C R L}$-radial reaction of the support front right wheel $(\mathrm{N}) ; Z_{S C R R}$-radial reaction of the supporting rear right wheel $(\mathrm{N})$; and $k$-raising the car (-). 


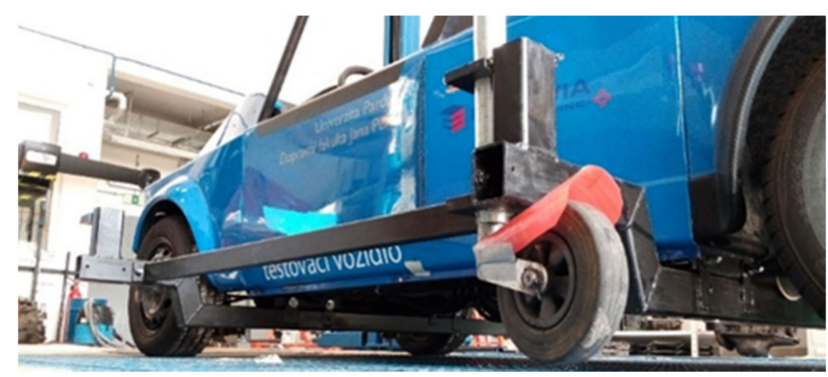

(a)

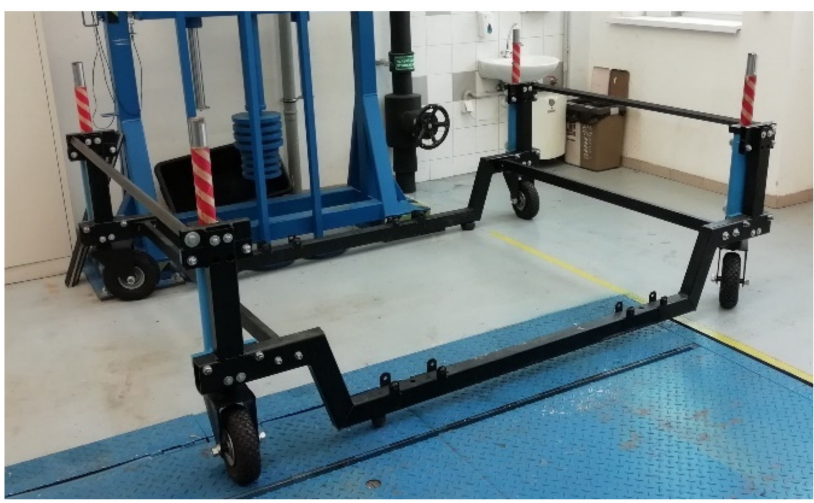

(b)

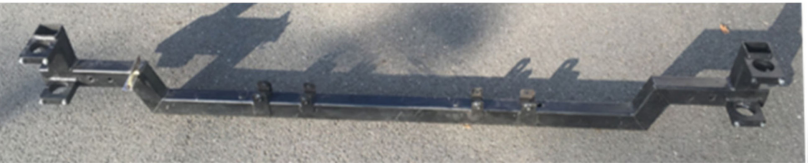

(c)

Figure 1. (a)-Experimental vehicle with the ASC system, (b) frame ASC, and (c) crossbar ASC.

\section{Load Determination on the ASC Frame Arms}

To carry out a strength analysis of the frame ASC crossbar, an input load was determined, depending upon the experimental vehicle's weight, driving mode and the degree of vehicle weight support. The input load of the wheel units, when the vehicle was stationary, was determined by weighing in a step-change in the radial reaction on the vehicle wheels. The load under the centrifugal force that occurs at the center of gravity of the system during turns, was determined by simulation in MSC Adams 2020 (Figure 2). The coordinates of the experimental vehicle's center of gravity were determined by the weighing and rolling rotation of the car on the tilting platform. The procedure for determining the height coordinate is given in [32]. All model bodies have defined their self-weight, stiffness and other characteristics. The tires have defined the pliability and damping, which have been detected on the VVCD drum tire testing machine [33]. All pins have a defined internal friction. The vehicle body was replaced by a mass point placed in the car's center of gravity. The bodywork is linked to the vehicle axles via suspension, and to the SC frame via a fixed connection. At the ends of both ASC crossbars, wheel units with deformed tires are located on the rotational links. The deformation characteristic is given in [15]. The wheel units rotated freely on cylindrical pins (with defined internal friction) around their vertical axis. These pins allowed the wheel units to move vertically. In this way, it is possible to achieve a reduction in the radial reaction of the vehicle wheels.

The mutual differences in the load on the support wheel units, in experimental measurements and simulation, are due to the fact that experimental measurements were defined by clearing down the clearances, and rubber components of the car chassis with the default value were used in the simulation model. The greatest error occurs when the tires are deformed at a low rate, especially at $20 \%$ of the car's unloading with SC, where the deviation is $5 \%$. The average deviation is $2.2 \%$, which can be considered as sufficient accuracy of 
the model. The comparison of the values obtained from the analytical calculation and the simulation values using MSC Adams together with the deviations, are depicted in Table 1.

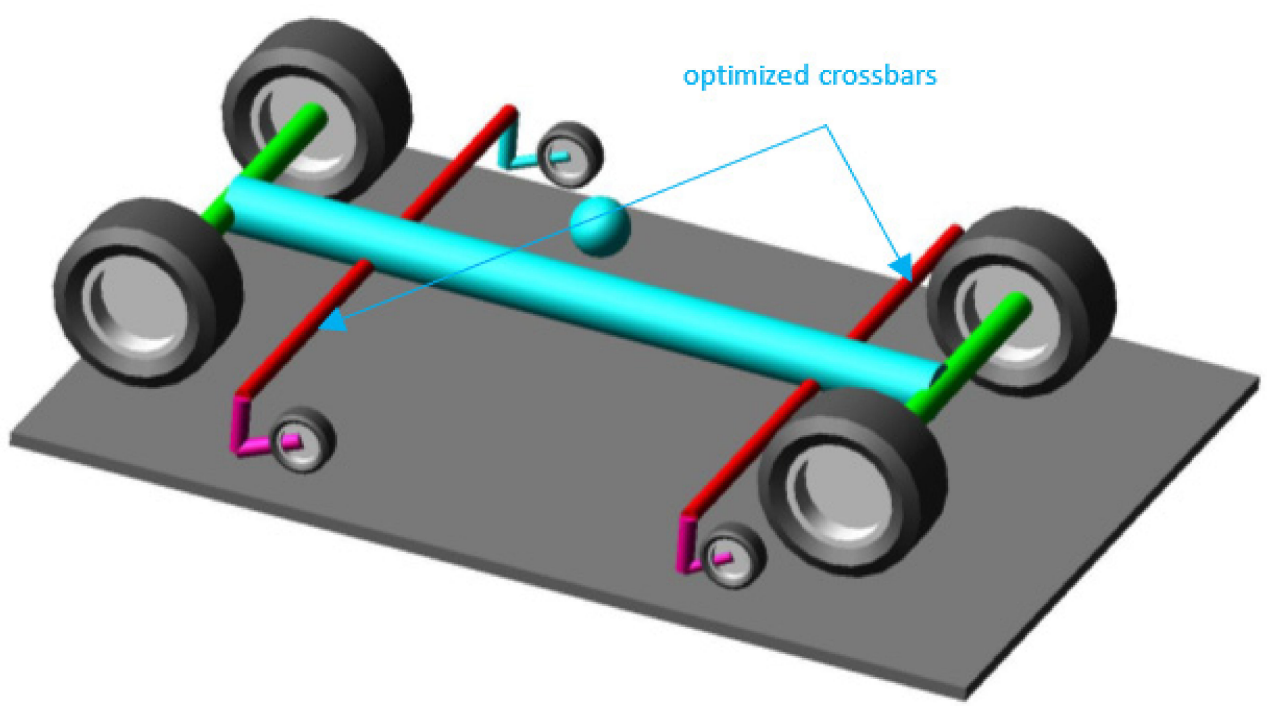

Figure 2. Vehicle model with ASC to determine the load.

In order to determine the change in the radial reaction of the ASC wheel units, a simulation of the vehicle roll rotation on the tilting platform was carried out. Its inclination divides the force of gravity applied to the car into two components: the component perpendicular to the tilting platform and the component parallel to the tilting platform. The parallel force component with the surface of the tilting platform has similar effects to the centrifugal force when cornering and increases with the increasing angle of platform roll until the vehicle slips. At the same time, the second component of the force, perpendicular to the tilting platform, which determines the amount of adhesive force on the wheels of the car, decreases with the tilting. Further processing of measurements on the tilting platform is described in [32].

In the first three seconds of the simulation, the wheel units are raised to the desired value, followed by a time interval of $7 \mathrm{~s}$ to tilt the platform to a maximum value of $\alpha \in<0^{\circ}$; $65^{\circ}>$. The time course of tilting the platform is shown in Figure 3.

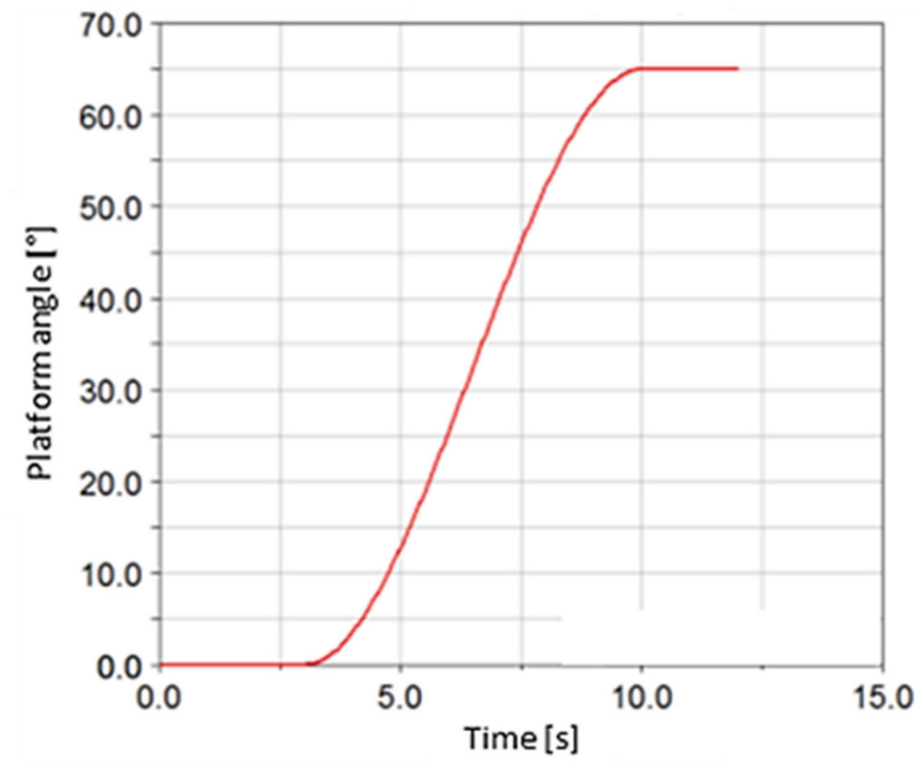

Figure 3. Tilt platform progress—-platform lift angle as a function of time. 
Simulations have been carried out for different load levels of the ASC wheel units (from $0 \%$ to $100 \%$ with a $20 \%$ step). A lift equal to zero radial reaction on the wheels is considered to be a $100 \%$ lift. The highest values achieved radial reactions on the front wheel units of the ASC at $100 \%$ lift and tilt. This situation cannot occur in the real operation, because if the car is unloaded for $100 \%$, it could not accelerate and therefore could not even drive a turn. From the experimental drive tests and measurements that have been carried out using this experimental vehicle, with the ASC system in the past [34], it is known that the lifting threshold, when the car wheels are still able to transmit tangential forces for accelerating, braking and cornering, is an $80 \%$ reduction of the radial reaction on the vehicle wheels (Figure 4).

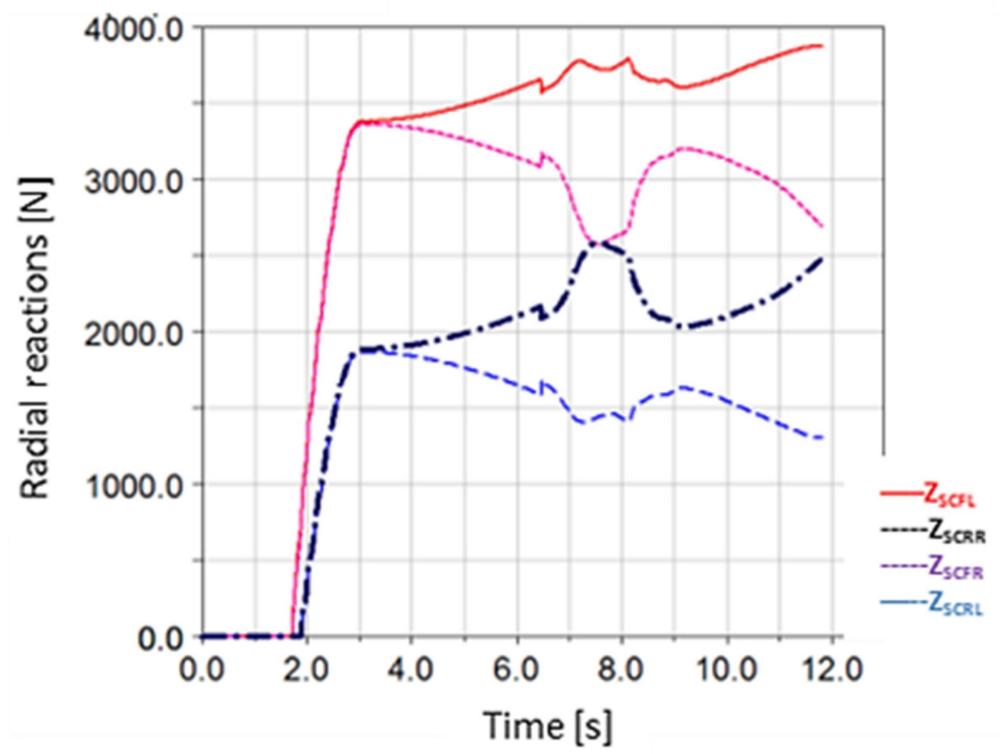

Figure 4. The course of the radial reactions of the ASC wheels when tilting on the tilting platform and $80 \%$ unweight of the vehicle wheels. $\left(Z_{S C F L}\right.$-radial reaction of the support front left wheel $(N)$; $Z_{S C F R}$-radial reaction of the support front right wheel $(\mathrm{N}) ; Z_{S C R L}$-radial reaction of the supporting rear left wheel $(\mathrm{N})$; and $Z_{S C R R}$ - radial reaction of the supporting rear right wheel).

At a higher relief, the wheels are already slipping, even during normal driving due to acceleration and braking, but also due to the road's ripples. Simulations on the tilting platform were also performed for $100 \%$ of the lift for completeness; however, for a comparison of the maximum radial reactions with the radial reactions resulting from the static car lift and the transverse force, maximum radial reactions on the SC wheels were taken into account at $80 \%$ of the unloading $Z_{S C F R}=3574 \mathrm{~N}$. The value $(80 \%)$ of the weight of the wheels was chosen as the most unfavorable condition, and the front right-hand wheel load multiplied by the factor of safety 1.6 was used.

\section{Results}

\subsection{Strength Study of the Original Design of the ASC Crossbar}

The strength of the frame was assessed according to the conservative standard for pressure vessels, ČSN 690010 [35]. The evaluation of the mechanical stress was performed by comparing the mechanical stress of the frame part with the maximum permissible stress for the material used [36]. The calculation of the maximum permissible $\sigma_{D O V}$ in the structure was drawn out according to the relation (1):

$$
\sigma_{D O V}=\tau \cdot \min \left\{\frac{R_{p} 0.2}{n_{T}} ; \frac{R_{m}}{n_{B}}\right\} \cdot \varphi,
$$


where $\sigma_{D O V}$ is the permissible mechanical stress $(\mathrm{MPa}), n_{T}$ is the coefficient of safety to yield stress (-), $\varphi$ is the coefficient of the weld joint, $R_{p} 0.2(\mathrm{MPa})$ is the contractual yield stress, $R_{m}$ is the breaking strength $(\mathrm{MPa})$, and $n_{b}$ is the coefficient of safety to breaking strength (-).

For nonlinear analysis, it is possible to evaluate the reserve against the limit states of the design being examined. In the MNA (materially non-linear) study, the von Mises bilinear model of the material was used and the limit state of plasticity was examined, and in the GMNA study, the limit state of stability loss was investigated. The indicator of this reserve is the so-called Load Factor, which is obtained from the loading characteristics of the selected structural node as the intersection of the tangent to the elastic part and the tangent to the plastic part of the characteristic. The structure will reach its limit if a load equal to the size of the original load, multiplied by the Load Factor, is applied to it. Consequently, if the Load Factor (reduced by the relevant factor of safety according to the Formula (2)) is greater than 1, the design is compliant with the limit state.

$$
L_{F D}=\min \left\{\frac{L_{F p l}}{n_{T}} ; \frac{L_{F s t}}{n_{u}}\right\} \cdot \varphi,
$$

where $L_{F D}$ is the permitted Load Factor (-) with a factor of safety, $L_{F P L}$ is the Load Factor of plasticity (-), $L_{F s t}$ is the Load Factor of stability $(-), n_{T}$ is proportionality coefficient (-), and $n_{u}$ is coefficient of ductility (-).

For the manufacturing of the frame, the construction steel S235JR (with parameters showcased in Table 2) was employed.

Table 2. Parameters of the material S235JR [36].

\begin{tabular}{cc}
\hline Parameter & Value \\
\hline Ultimate tensile strength (MPa) & 360 \\
Yield strength (MPa) & 235 \\
Density (kg.m $\left.{ }^{-3}\right)$ & 7850 \\
Ductility (\%) & 26 \\
Poisson's ratio (-) & 0.3 \\
Young's modulus (MPa) & 210,000 \\
\hline
\end{tabular}

The ASC frame attachment was realized by limiting the vertical movement applied to the bearing surface, where the car frame sits on the ASC crossbar. The implemented displacement limitation is a suitable simplification prerequisite, but it is well suited to real construction. Another fixture was applied to the split lines on the frame's mounts. From the outer side of the frame mount, the split line simulates the M10 bolt washer with an external diameter of $20 \mathrm{~mm}$ DIN 125a. From the inside, the split line covers the entire surface of the mount above the crossbar profile, that is the area that is in contact with the car frame. The condition of full tightening of the bolts was represented by removing all degrees of freedom at the mounting point (Figure 5).

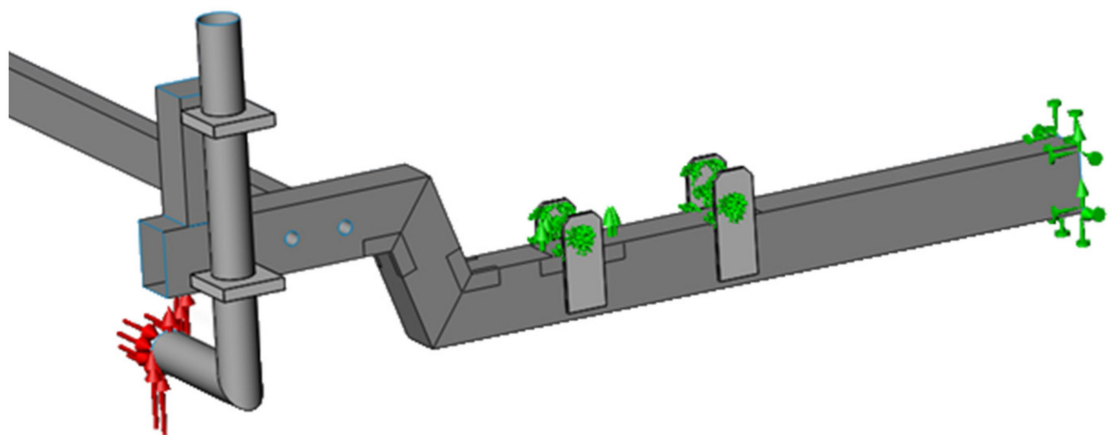

Figure 5. Mounting and loading of the ASC crossbar. 
The load was defined as the force applied to the wheel units with the caster. The pipes are only used as a connection between the point of application of the real force and the clamp joints. The force in the analysis is used as even, linearly rising to its nominal value. The frame load was applied to the ends of the bent tubes simulating the wheel units and their caster. These pipes were fixed in clamping joints. Vertical and horizontal forces applied to the end edge of the bent tubes were used as a load. The vertical force is determined by the factor of safety and maximum radial reaction obtained from the simulations in the MSC Adams software, for the appropriate steering angle of the ASC.

The horizontal force represents the rolling resistance and always acts against the direction of rolling of the individual wheels. Rolling resistance is caused by the deformation of the rubber wheel on a rigid road $[9,11,33]$ and is defined according to the relation (3)

$$
F_{T}=Z_{k} \cdot \frac{\xi}{r}
$$

where $F_{T}$ is the rolling resistance force $(\mathrm{N}), Z_{S C K}$ is the radial reaction $(\mathrm{N}), \xi$ is the rolling resistance arm $1.6 \mathrm{~mm}$, and $r$ is the radius of the support wheel ASC (mm).

The mesh was created using a SolidWorks 2022 generator. Subsequently, critical areas of the structure (Figure 6) were pointed out, where the mesh was refined to achieve more accurate results. The mesh size of both the standard and refined regions have been optimized for the best possible ratio between the calculation speed and the accuracy of the results (Figure 7 ).
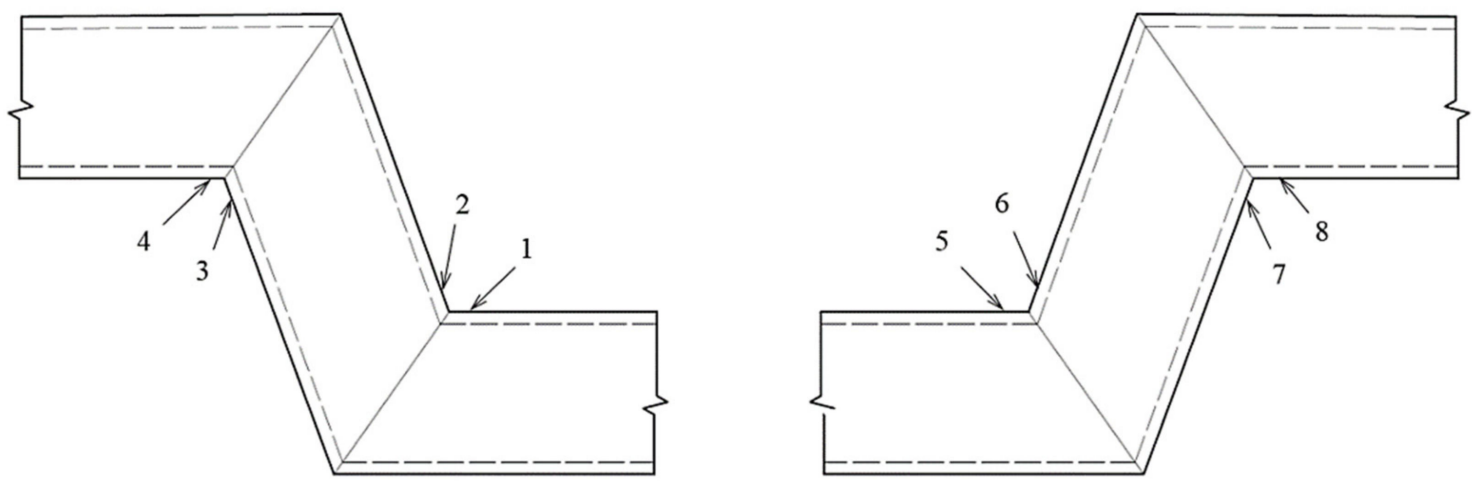

Figure 6. Critical points on the crossbar.

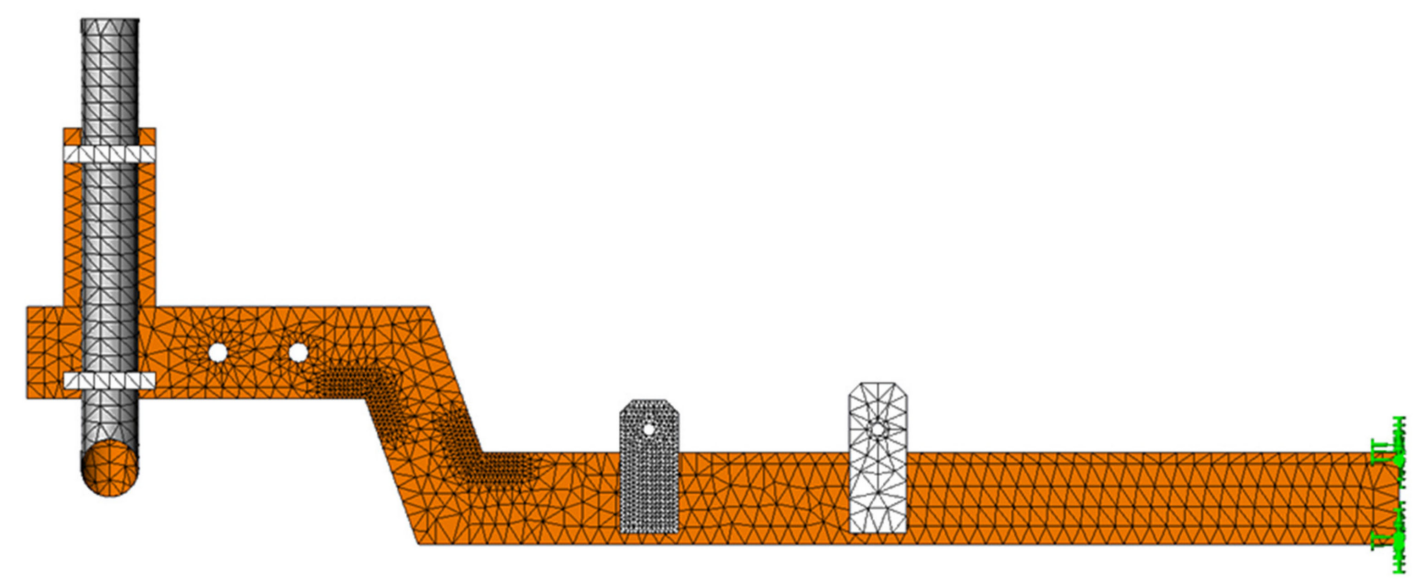

Figure 7. The refined meshing of the half of the ASC crossbar.

Subsequently, a geometrically and materially nonlinear analysis (GMNA) was performed for the frame with the wheels turned to face the outside and the inside of the 
car, forward and rearward (Table 3). The most unfavourable variant was the variant with the wheels turned to face the outside of the car; therefore, this position was used in all subsequent analyses.

Table 3. Stresses at critical points of the crossbar (MPa).

\begin{tabular}{ccccc}
\hline \multirow{2}{*}{ Critical Point } & \multicolumn{4}{c}{ Rotation of Wheel Units } \\
\cline { 2 - 5 } & Forwards & Backwards & Outwards & Inwards \\
\hline 1 & 111 & 80 & 128 & 43 \\
2 & 119 & 69 & 130 & 36 \\
3 & 67 & 136 & 140 & 49 \\
4 & 66 & 120 & 134 & 41 \\
5 & 82 & 129 & 143 & 56 \\
6 & 78 & 145 & 152 & 56 \\
7 & 108 & 66 & 125 & 23 \\
8 & 73 & 60 & 101 & 16 \\
\hline
\end{tabular}

The ASC crossbar design is suitable for a reserve against limit states, but the mechanical stress at several locations exceeds the maximum allowable stress. The highest stress of the structure was calculated at the node 46439 (Figure 8).

von Mises (N/mm^2 (MPa)]
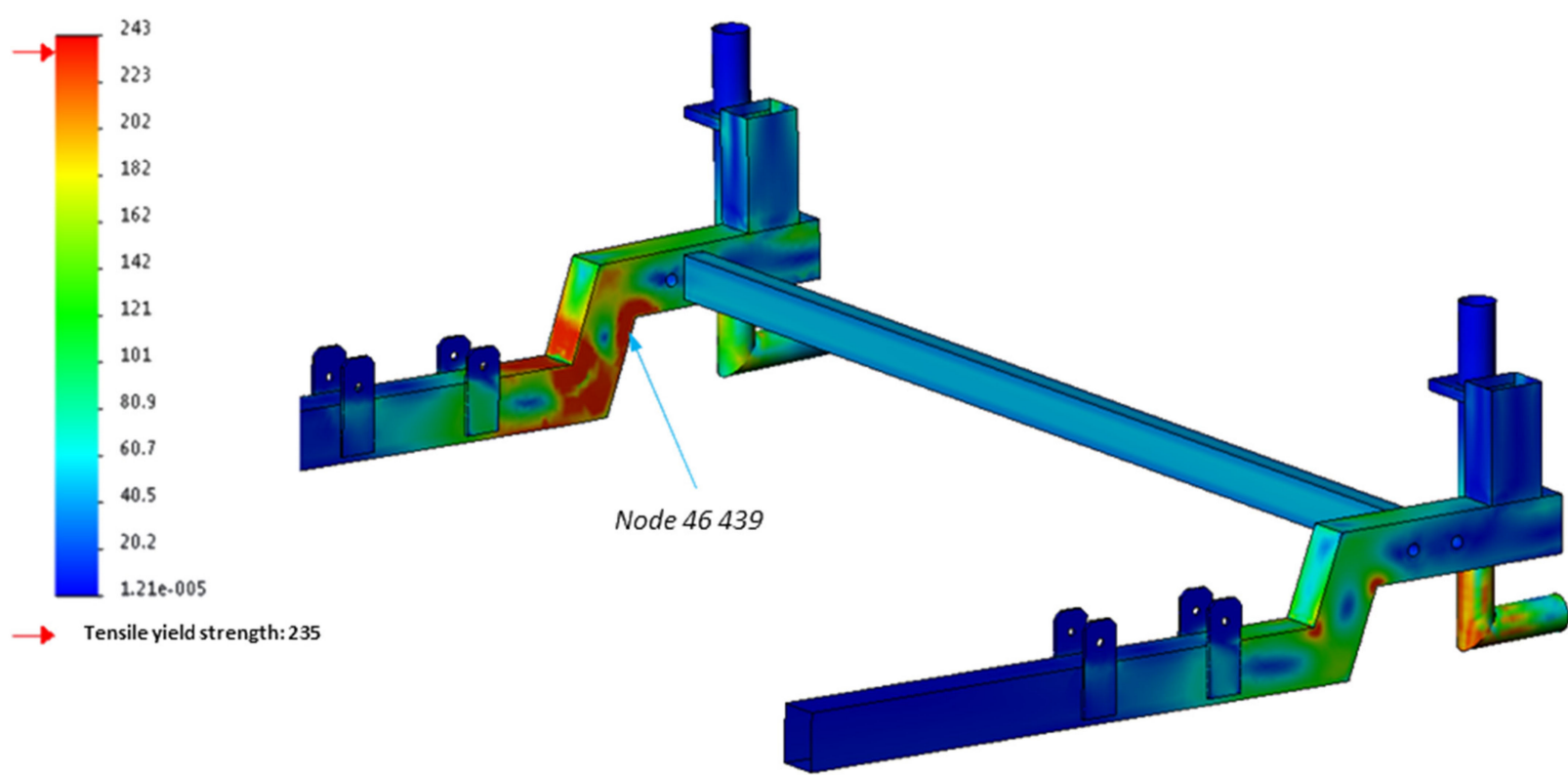

Figure 8. Stress in the original ASC crossbar in case of collapse.

To obtain the load degree value for the limit state of stability of $L_{F s t}$, tangents to the elastic and plastic part of the curve were drawn and the value of the Load Factor at their intersection point (Figure 9) was read. The value $L_{F s t}$ from the GMNA analysis for the stability limit state of the original frame solution is 3.86 . 


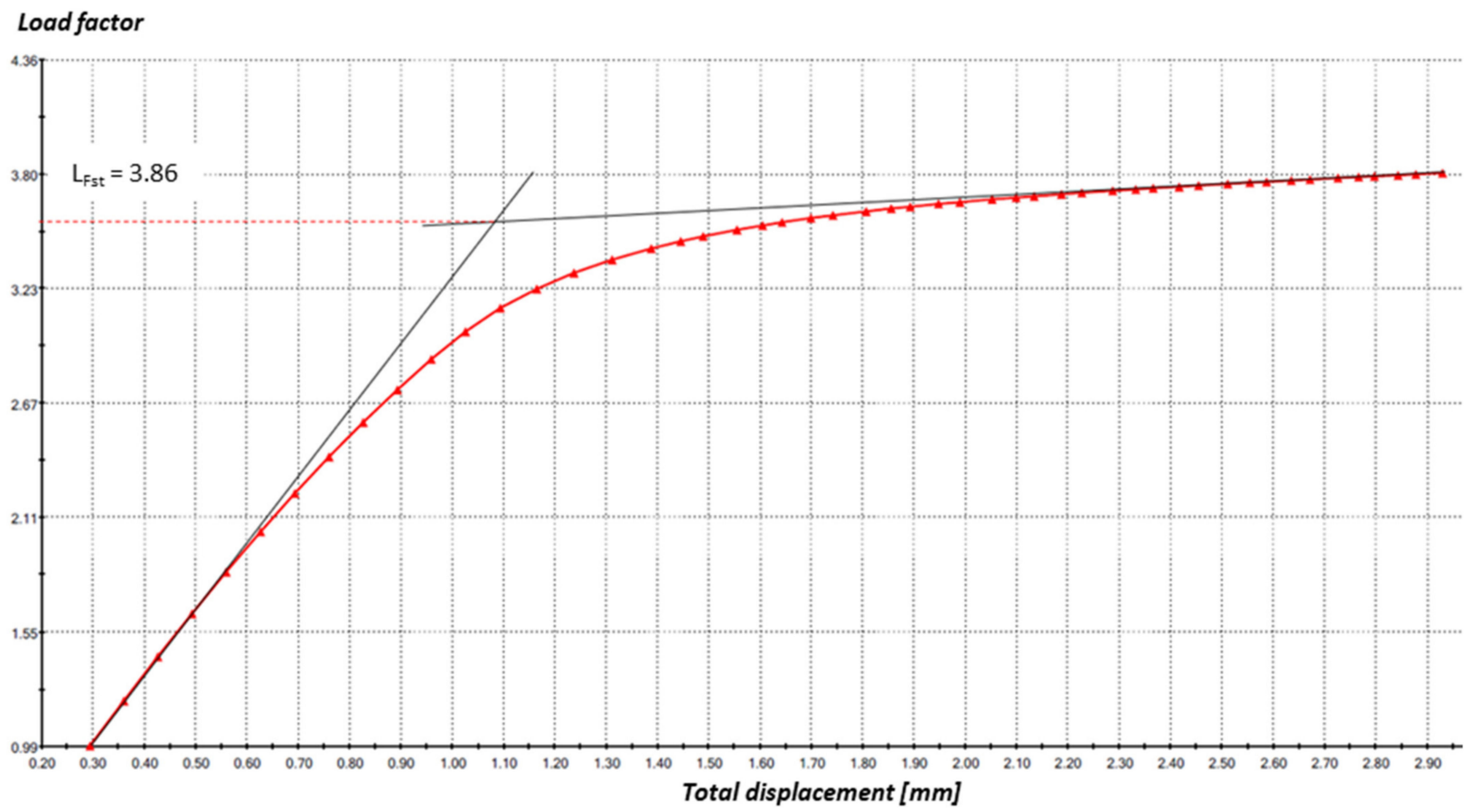

Figure 9. Load characteristics at the node 46439.

The permissible Load Factor calculated according to the Formula (2) is greater than 1 , which means that this concept of the frame in terms of limit states complies with the requirements. Even though the maximum permissible load on the ASC wheels can be $13 \%$ higher for compliance, the design does not comply with the maximum allowable stress in certain areas; therefore, its optimization was also undertaken.

\subsection{Optimization of the ASC Frame Crossbar}

Based on the results from the analysis of the current state, the shape design of the ASC crossbar was optimized. The modification that has been proposed on the frame is the addition of triangular and rectangular reinforcements to the welding points of the crossbars, which will absorb some quantity of the stress peak, and therefore drop the above concentration observed at the top of the hollow section joints (Figure 10).

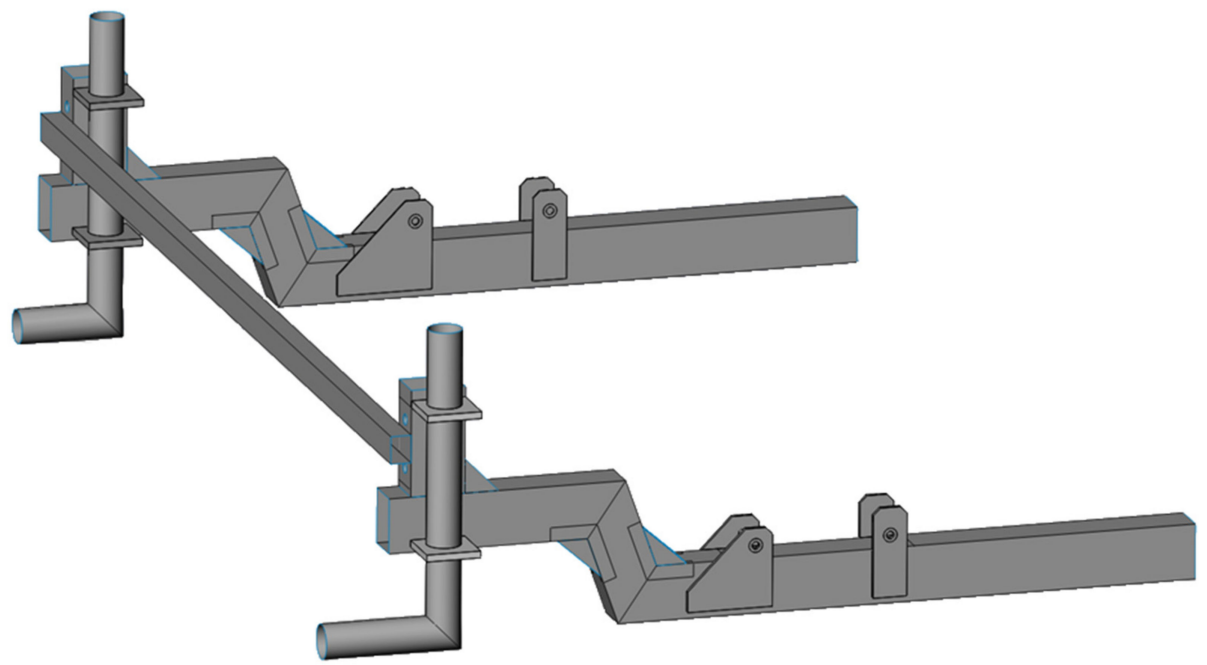

Figure 10. Implementation of crossbar reinforcement. 
The reinforcements were selected in each corner as double, placed on the edges of the hollow section and reinforced from the outside by a rectangular flat sheet. Only the reinforcements of the vertical hollow sections, to which the side members were attached, were designed as double triangles, to solely facilitate the assembly of the side member using bolts. Their thickness, after the previous analysis, was chosen to be the same as the thickness of the reinforced parts, i.e., $4 \mathrm{~mm}$. Consequently, the arrangement of the crossbar welds was optimized so that the weld did not pass through the critical point with the maximum stress value (Figure 11).

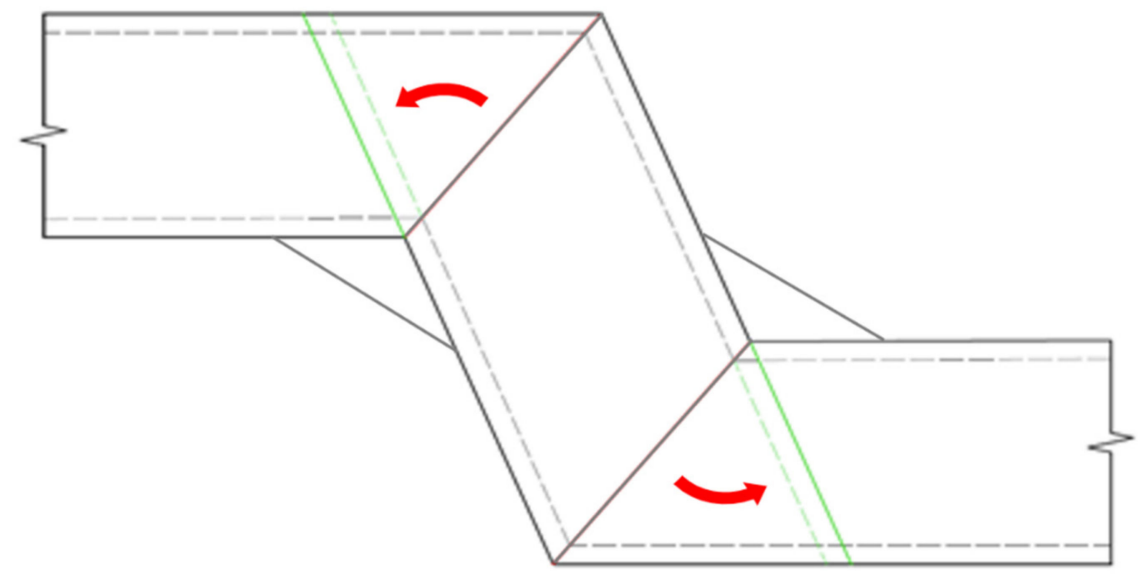

Figure 11. Implementation of crossbar reinforcement, - the original state, - a new state.

We carried out a geometrically and materially nonlinear analysis (GMNA) in the same way as in the original design of the ASC frame. The actual value of the highest von Mises stress did not exceed the strength, $\sigma_{D}=105 \mathrm{MPa}$. The distribution of the mechanical stress in the steel structure is shown in Figure 12.

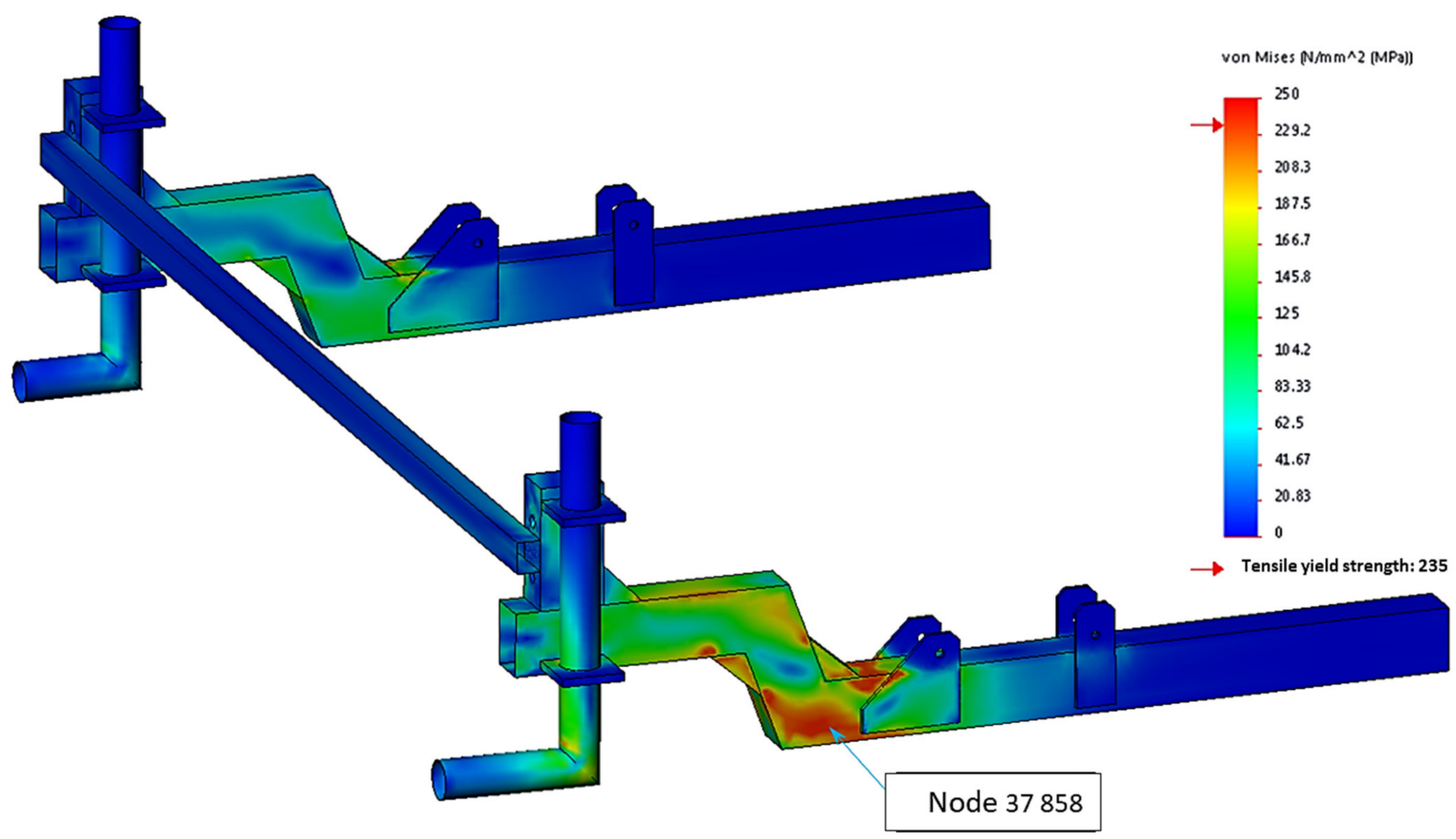

Figure 12. Von Mises's stress distribution in the optimized ASC crossbar. 
The value $L_{F s t}$ of the GMNA analysis for the limit state of the newly proposed frame solution is 3.94. The strength evaluation, in terms of limit states, and the calculation of the permissible load was carried out according to Formula (2), $L_{F D}=1.15$ (Figure 13). The permissible Load Factor is greater than 1, so the design of the ASC frame crossbar fits in terms of its strength. The maximum permissible load on the SC wheels can be $15 \%$ higher for compliance. The structure conforms to the limits of plasticity and stability, and the maximum allowable stress.

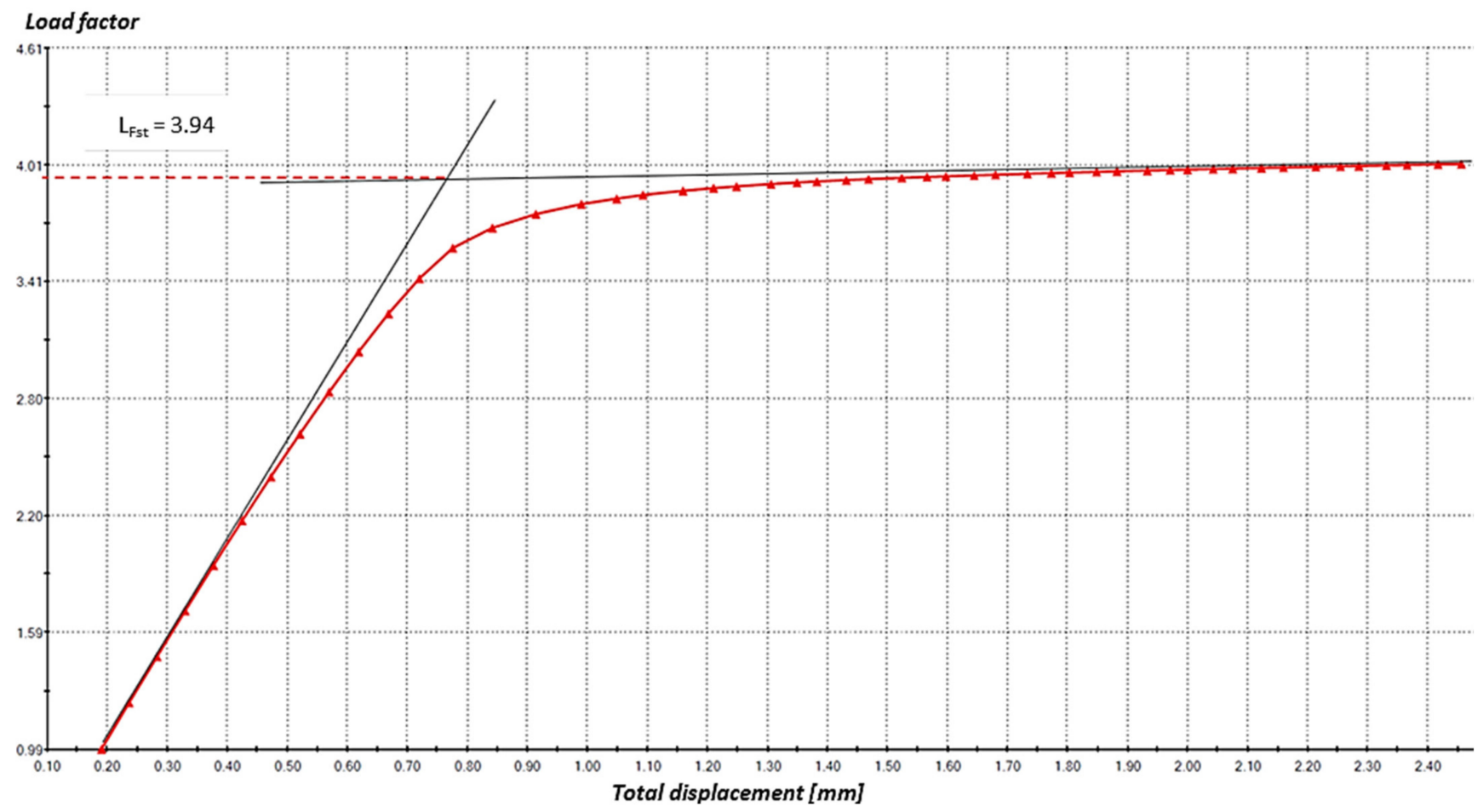

Figure 13. Load characteristics at the node 37858.

\subsection{Optimization of the Material Used}

As an alternative to the original S235JR material, S355J0 steel and EN AW-6060 T6 aluminium alloy were conjointly investigated.

\subsubsection{Steel S355J0}

The construction steel S355J0 was selected as the first material for the frame, which is structurally and materially optimized. As with S235JR steel, it is structural non-alloy steel with the same specific weight, but with a greater yield and limit strength than the original S235JR steel. As a result, thinner profiles can be used while maintaining the strength of the frame, resulting in its weight reduction. Table 4 lists the parameters of the named material.

Table 4. Basic parameters of steel S355J0 [37].

\begin{tabular}{cc}
\hline Parameter & Value \\
\hline Ultimate tensile strength (MPa) & 470 \\
Yield strength (MPa) & 355 \\
Density (kg.m $^{-3}$ ) & 7850 \\
Ductility (\%) & 22 \\
Poisson's ratio (-) & 0.3 \\
Young's modulus (MPa) & 210,000 \\
\hline
\end{tabular}

The allowable stress of the structurally optimized frame for steel S355J0 is in accordance with the Formula (1), $\sigma_{D O V}=137 \mathrm{MPa}$. The modified frame structure model was 
subjected to a geometrically and materially non-linear strength study. The execution procedure was similar to that of the original frame design. The distribution of the mechanical stress at node 37451 is shown in Figure 14. In particular, Figure 15 shows the loading characteristics at the node 37 451, with maximum mechanical stress.

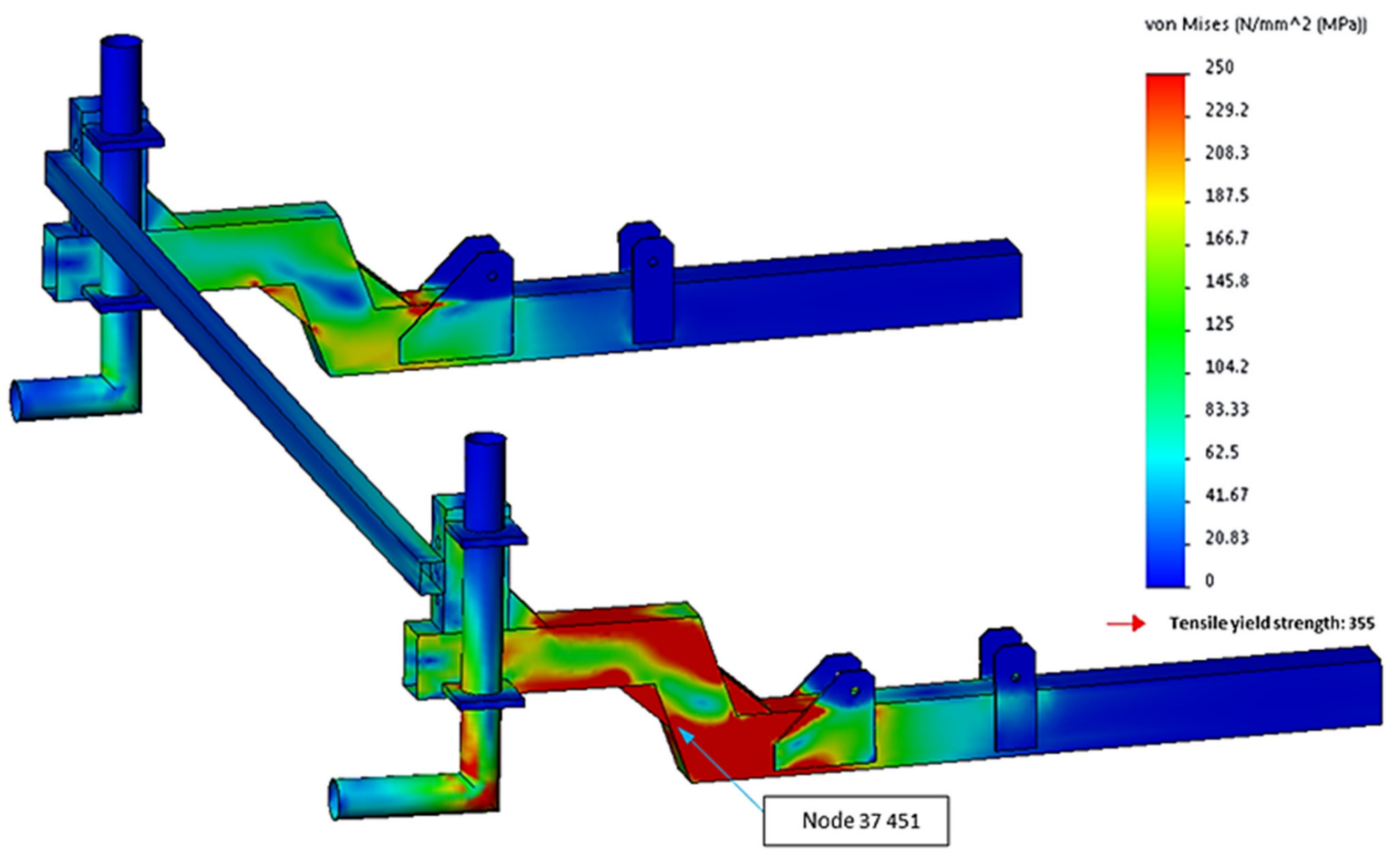

Figure 14. The mechanical stress in the structurally and materially (S355J0) optimized frame solution at the limit state of stability.

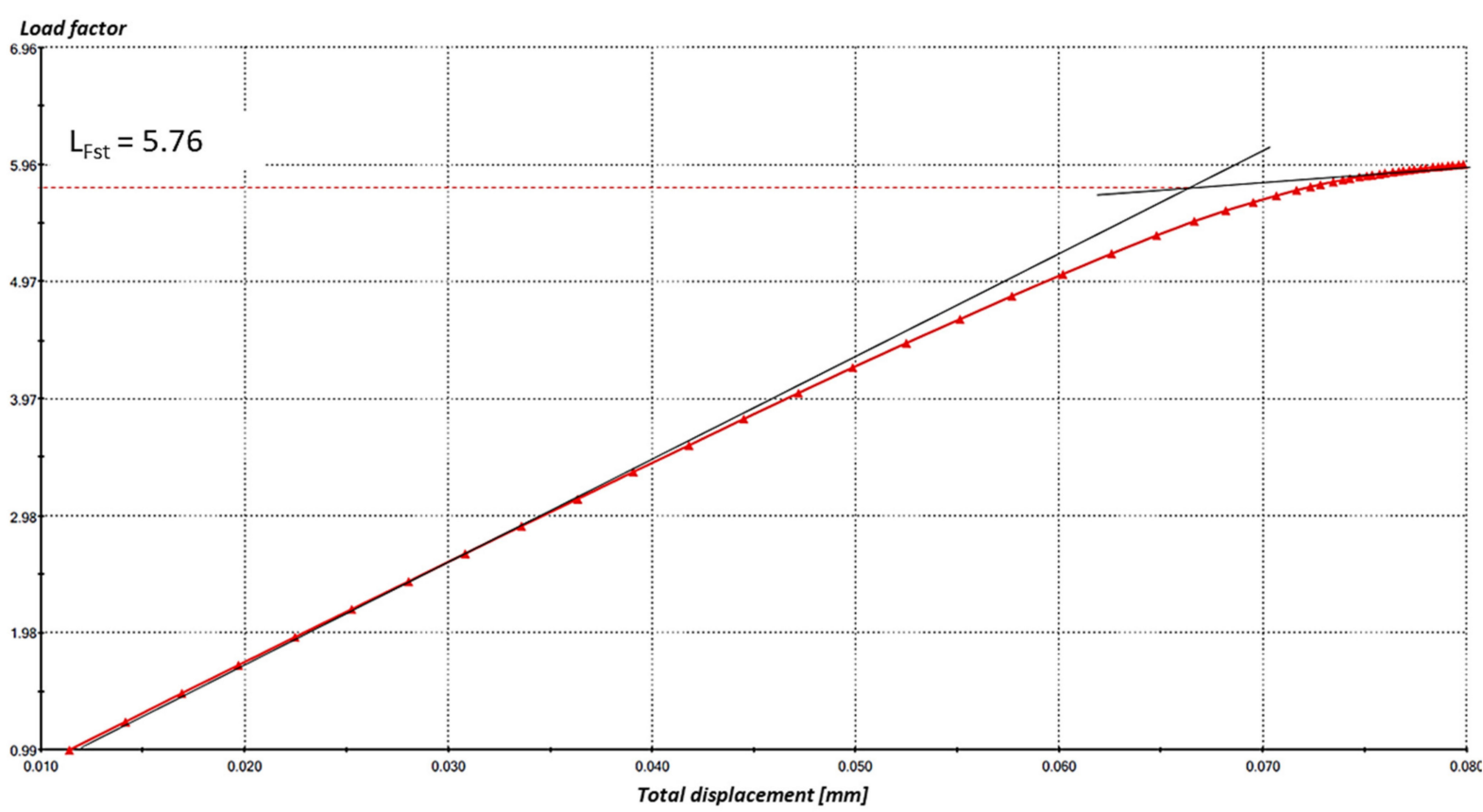

Figure 15. Load characteristics at the node 37451.

The strength, in terms of limit states, and the calculation of the permissible load were evaluated according to Formula (2) and $L_{F D}=1,68$. The permissible Load Factor is greater than 1 , so this frame concept firmly fits. The maximum permissible load on the SC wheels 
can increase by $68 \%$ for compliance. The structure, therefore, complies with the limits of plasticity and stability and the maximum allowable stress.

\subsubsection{Aluminium Alloy EN AW-6060 T6}

Aluminium alloy suitable for the construction of the frame of the alternative SkidCar system was chosen (EN AW-6060 T6 designation), according to ČN EN 573 [38], with the chemical designation AlMgSi0. The T6 label indicates the heat treatment of the alloy, in this case dissolving, annealing and artificial ageing. The aluminium alloy EN AW-6060 T6 is sufficiently machinable, and has sufficient strength and hardness for use on the frame of the alternative SkidCar system. Not least, its corrosion resistance is sufficient and can be increased by anodic oxidation (by anodizing). The weldability of this alloy is good; it can be welded by MIG or TIG alternating current methods.

The strength of this material is lower than that of the currently used steel, so the profile of the crossbars has been changed from PR OBD $-80 \times 60 \times 5$ to PR OBD-100 $\times 80 \times 6$. As the width of the proposed profiles is larger, it is recommended to change the width of the mounts on the experimental car, which sit on the upper surface of the crossbars, to the same width, i.e., $80 \mathrm{~mm}$. Welds usually have a lower strength than the surrounding material, so it is advisable to subject the weldment to dissolving, annealing and curing, to obtain the original strength in the weld area. The basic parameters of the material are shown in Table 5.

Table 5. Basic parameters of aluminium EN AW-6060 T6 [38].

\begin{tabular}{cc}
\hline Parameter & Value \\
\hline Ultimate tensile strength $(\mathrm{MPa})$ & 170 \\
Yield strength $(\mathrm{MPa})$ & 140 \\
Density $\left(\mathrm{kg} \cdot \mathrm{m}^{-3}\right)$ & 2700 \\
Ductility $(\%)$ & 10 \\
Poisson's ratio $(-)$ & 0.33 \\
Young's modulus $(\mathrm{MPa})$ & 70,000 \\
\hline
\end{tabular}

The allowable stress of the structurally optimized frame for aluminium alloy EN AW-6060 T6 is determined according to the Formula (1) $\sigma_{D O V}=50 \mathrm{MPa}$. The modified frame structure model was subjected to a geometrically and materially non-linear strength analysis (Figure 16). The execution procedure is similar to that of the original frame design.

To obtain the Load Factor value for loss of stability, tangents to the elastic and plastic part of the curve were created again, and the value of their intersection was read. The value $L_{F s t}$ was concerning this case (3.50). Figure 17 shows the mechanical stress in the critical area (point 53 719,) for the entered value of the load used for the GMNA analysis.

According to the GMNA analysis, the frame has not exceeded the maximum permissible stress. From this point of view, the aluminium alloy frame complies with the requirement. The value of the permissible Load Factor $\left(L_{F D}=1.02\right)$ calculated according to relation 2 is greater than 1; therefore, this concept of aluminium alloy frame fits from the perspective of strength. The maximum permissible load can only increase by $2 \%$ for compliance with the limit conditions. The structure is conformed to the limits of plasticity and stability and the maximum allowable stress.Within the material optimization, two materials were proposed from which the frame of the alternative SkidCar system can be manufactured. The first was considered as stronger steel S355J0. Since this steel is stronger than the S235JR steel from which the original ASC frame solution was designed, it resulted in even more significant weight savings (Table 6). 


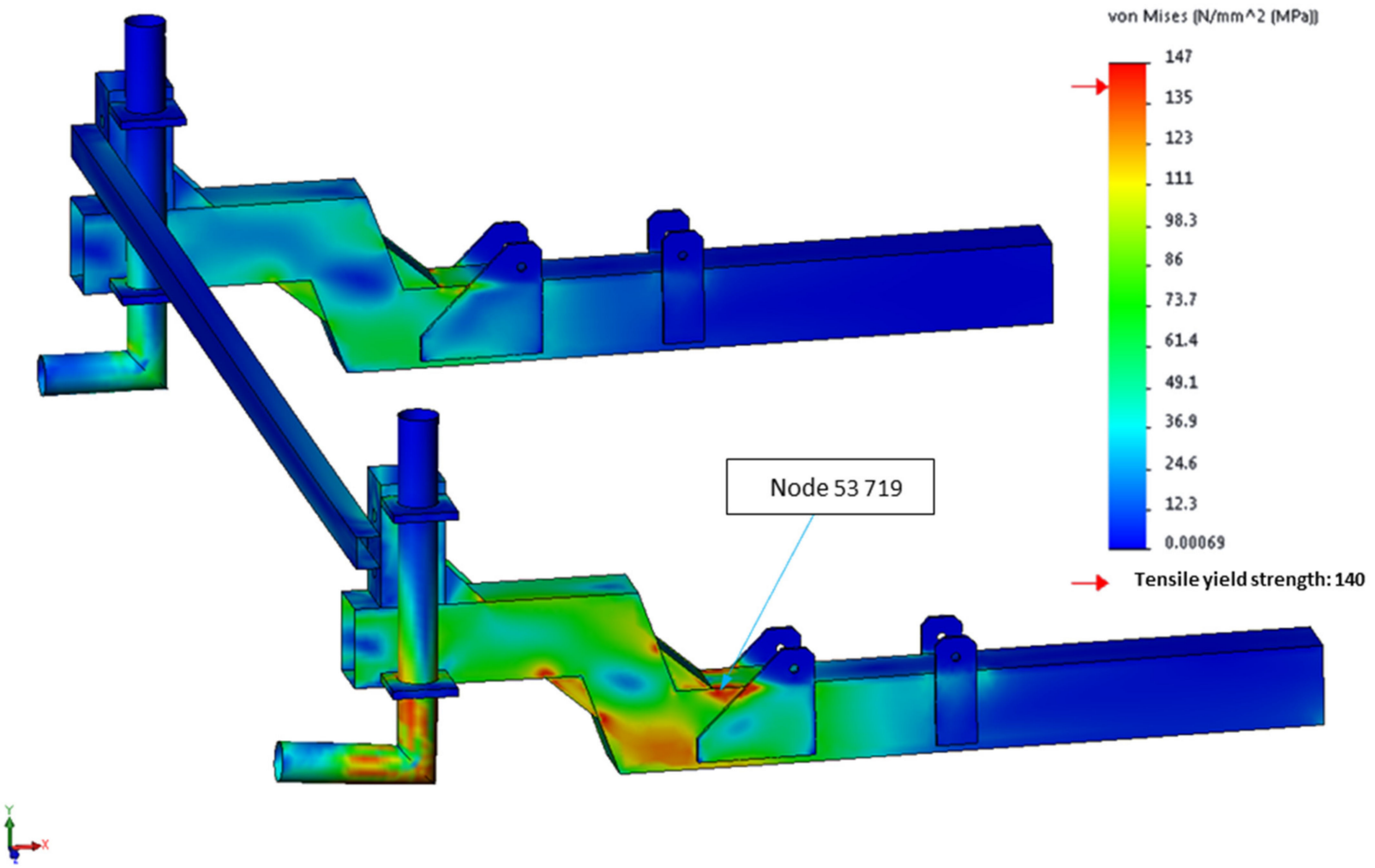

Figure 16. Von Mises's stress distribution in the optimized ASC crossbar made of aluminium material.

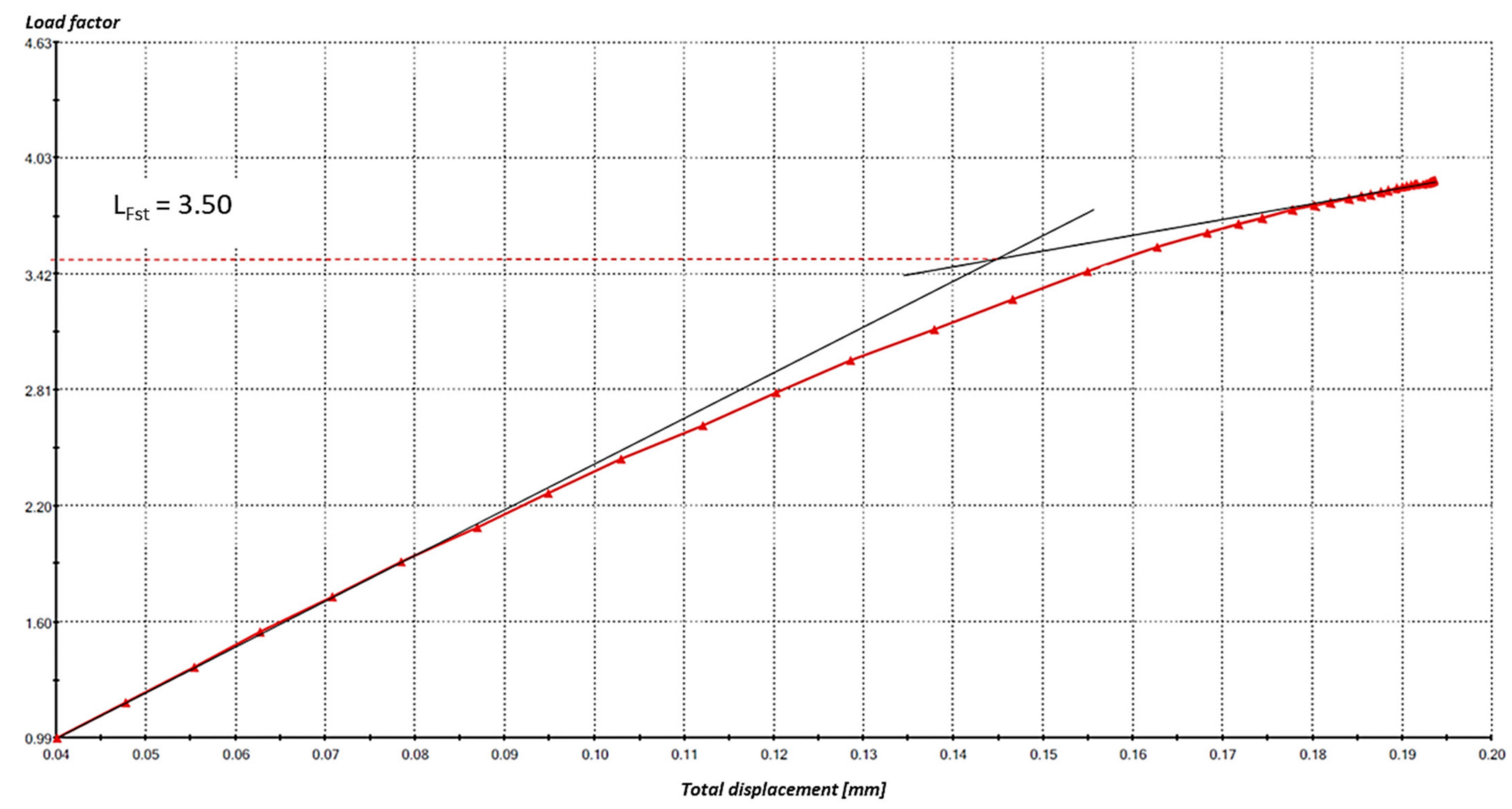

Figure 17. Load characteristics of the node 53719. 
Table 6. Comparison of thickness and mass of crossbars, before and after design optimization.

\begin{tabular}{ccccc}
\hline $\begin{array}{c}\text { Original Thickness } \\
(\mathbf{m m})\end{array}$ & $\begin{array}{c}\text { Thickness after the } \\
\text { Optimization } \\
(\mathbf{m m})\end{array}$ & $\begin{array}{c}\text { Original Weight } \\
\mathbf{( k g})\end{array}$ & $\begin{array}{c}\text { Weight after the } \\
\text { Optimization } \\
(\mathbf{k g})\end{array}$ & $\begin{array}{c}\text { Difference } \\
(\mathbf{\%})\end{array}$ \\
\hline 5 & 4 & 32.6 & 29.1 & 10.5 \\
\hline
\end{tabular}

Table 7 shows the crossbar weights after optimization, for S355J0 steel, and a comparison of these parameters with the original weights and thicknesses before optimization (S235JR steel). By using stronger steel, all parts of the frame can be thinner and thus save $8.6 \mathrm{~kg}$, i.e., $26.3 \%$ of the weight using S355J0 steel.

Table 7. Comparison of the thickness and weight of frame parts using original steel S235JR solution and stronger S355J0 steel.

\begin{tabular}{ccccc}
\hline $\begin{array}{c}\text { Original Thickness } \\
(\mathbf{m m})\end{array}$ & $\begin{array}{c}\text { Thickness after the } \\
\text { Optimization } \\
(\mathbf{m m})\end{array}$ & $\begin{array}{c}\text { Original Weight } \\
\mathbf{( k g )}\end{array}$ & $\begin{array}{c}\text { Weight after the } \\
\text { Optimization } \\
\mathbf{( k g )}\end{array}$ & $\begin{array}{c}\text { Difference } \\
\mathbf{( \% )}\end{array}$ \\
\hline 5 & 3 & 32.6 & 24.0 & 26.3 \\
\hline
\end{tabular}

The second alternative material for the SC frame was chosen as an aluminium alloy, with the designation EN AW-6060 T6. This alloy has lower strength characteristics than the original material. It was therefore necessary to use larger PR OBD profiles $100 \times 80 \times 6$ with a greater thickness than the crossbars. However, even so, the greatest weight savings were made.

Table 7 shows the thickness and weights of the frame and frame components using the original S235JR steel, and the design solution using aluminium alloy and a modified structure.

As it can be observed from Table $8,45.4 \%$ of the weight of the frame was reduced, while maintaining the required strength, to $17.8 \mathrm{~kg}$ by the design modifications and replacement of the original S235JR steel with EN AW-6060 T6 aluminium. The disadvantage of this solution is the significantly higher economic cost of the frame material than when using structural steel.

Table 8. Comparison of the thicknesses and weights of the frame parts using the steel of the original S235JR solution and the aluminium alloy EN AW-6060 T6.

\begin{tabular}{ccccc}
\hline $\begin{array}{c}\text { Original Thickness } \\
(\mathbf{m m})\end{array}$ & $\begin{array}{c}\text { Thickness after the } \\
\text { Optimization } \\
(\mathbf{m m})\end{array}$ & $\begin{array}{c}\text { Original Weight } \\
\mathbf{( k g )}\end{array}$ & $\begin{array}{c}\text { Weight after the } \\
\text { Optimization } \\
\mathbf{( k g )}\end{array}$ & $\begin{array}{c}\text { Difference } \\
\mathbf{( \% )}\end{array}$ \\
\hline 5 & 6 & 32.6 & 17.8 & 45.4 \\
\hline
\end{tabular}

\section{Discussion}

Based on the simulations performed in MSC Adams 2019, the maximum load applied to the wheels of the alternative SkidCar system was determined. The load value obtained this way, was used as the input value of the ASC frame load to perform strength FEM analyses in SolidWorks 2022. After comparing the results of the linear analyses of the original design of the frame crossbars for, respectively, forward, reverse and both sides driving modes, it was assessed that the highest stress on the frame occurs when the car moves in the transversal direction with the wheels turned away from the car. This driving mode was considered in all other stress-deformation analyses of the original and optimized frame designs. After evaluating the strength of the original frame solution, the frame complies with the limit states point of view, but the stress at several locations exceeds the maximum allowable stress. Through an optimization process, frame reinforcements were added to the areas with a high-stress concentration. This allowed the thickness of the 
crossbar wall to be dropped to $4 \mathrm{~mm}$, thereupon ensuring a decrease in the crossbar weight, by $10.5 \%$, using the current material (S235JR), while maintaining the original strength of the frame. From the above findings, it is clearly visible that during further frame adjustment, it is possible to reduce the wall thickness from $5 \mathrm{~mm}$ to $3 \mathrm{~mm}$ using S355J0 steel, and thus save the weight of $26.3 \%$ compared to the original state. When using EN AW-6060 T6 material, the thickness of the crossbar profile had to be increased to $6 \mathrm{~mm}$. However, the weight of the crossbar decreased by $45.4 \%$, while maintaining the original strength.

\section{Conclusions}

The frame crossbar design of the alternative SkidCar system was evaluated and optimized, in the present paper. The load on the frame wheels detected by MSC Adams will cause strain on the frame arms, which is evaluated by the mechanical stress and limit states. The loading of the auxiliary wheels of the alternative SkidCar frame was determined by experimental measurement and used for the validation of the model in MSC Adams. The strength analysis was evaluated from the perspective of mechanical stress and limit states and is in satisfactory condition.

Subsequently, the design modifications were investigated and led to the following core results:

- Weight reduction of the frame;

- A more uniform distribution of stress in the area of concentration;

- Increase the stiffness of the entire frame;

- Improve the stability of the frame.

Based on the results, it can be concluded that:

- According to the [35] standard applied, all proposed optimization solutions are compliant in terms of strength-the design-modified frame using the original material, the steel of higher strength and the aluminium alloy;

- $\quad$ Significant weight savings have been recorded;

- The functionality and compatibility of the frame with the experimental car have not been limited or affected.

Recommendations for further research:

- The subject of further examination can be the evaluation of the fatigue and durability of the frame, detailed modeling and evaluation of the notches and welds of the structure;

- It would also be advisable to design a frame for composite material;

- The created model can be further developed, for example, by using a different type of SC wheel, considering the flexible behavior of the material or changing parameters for the use of the alternative SkidCar system on different cars;

- It would also be possible to build up a model of a car with an alternative SkidCar system that overcomes road irregularities, and feed this force impulse into the FEM analyses. Furthermore, it would be appropriate to deal with the dynamic analyses of the system.

The optimized frame will help improve the accuracy of the vehicle stability measurements during driving tests, thereby increasing the safety of road vehicles in a facilitated manner and enabling improvements to car autonomous driving systems. The use of an optimized alternative SkidCar frame is a means of experimental verification of the research findings in the field of vehicle driving stability.

Author Contributions: Conceptualization, P.J. and J.B.; methodology, J.B.; software, P.J.; validation, P.J. and J.B.; formal analysis, P.J. and J.B.; investigation, P.J.; resources, P.J.; data curation, J.B.; writingoriginal draft preparation, P.J.; writing—review and editing, P.J. and B.S.S.T.; visualization, P.J.; supervision, J.B.; project administration, P.J.; funding acquisition, J.B. All authors have read and agreed to the published version of the manuscript.

Funding: This research received no external funding. 
Institutional Review Board Statement: Not applicable.

Informed Consent Statement: Not applicable.

Data Availability Statement: The data presented in this study are available on request from the corresponding author.

Conflicts of Interest: The authors declare no conflict of interest.

\section{References}

1. Li, X.; Oviedo-Trespalacios, O.; Rakotonirainy, A.; Ya, X. Collision risk management of cognitively distracted drivers in a car-following situation. Transp. Res. Part F Traffic Psychol. Behav. 2019, 60, 288-298. [CrossRef]

2. Yoon, Y.; Kim, A. Resolving Persistent Packet Collisions through Broadcast Feedback in Cellular V2X Communication. Future Internet 2021, 13, 211. [CrossRef]

3. Prochowski, L.; Ziubiński, M.; Szwajkowski, P.; Gidlewski, M.; Pusty, T.; Stańczyk, T.L. Impact of Control System Model Parameters on the Obstacle Avoidance by an Autonomous Car-Trailer Unit: Research Results. Energies 2021, 14, 2958. [CrossRef]

4. Ameen, H.A.; Mahamad, A.K.; Saon, S.; Malik, R.S.; Kareem, Z.H.; Bin Ahmadon, M.A.; Yamaguchi, S. Identification of Driving Safety Profiles in Vehicle to Vehicle Communication System Based on Vehicle OBD Information. Information 2021, $12,194$. [CrossRef]

5. Maldonado, J.; Giefer, L.A. A Comparison of Bottom-Up Models for Spatial Saliency Predictions in Autonomous Driving. Sensors 2021, 21, 6825. [CrossRef]

6. Choi, Y.; Lee, W.; Kim, J.; Yoo, J. A Variable-Sampling Time Model Predictive Control Algorithm for Improving Path-Tracking Performance of a Vehicle. Sensors 2021, 21, 6845. [CrossRef]

7. Ma, H.; Chu, L.; Guo, J.; Wang, J.; Guo, C. Cooperative Adaptive Cruise Control Strategy Optimization for Electric Vehicles Based on SA-PSO With Model Predictive Control. IEEE Access 2020, 8, 225745-225756. [CrossRef]

8. Taherian, S.; Halder, K.; Dixit, S.; Fallah, S. Autonomous Collision Avoidance Using MPC with LQR-Based Weight Transformation. Sensors 2021, 21, 4296. [CrossRef]

9. Dendaluce, M.; Iglesias, I.; Martin, A.; Prieto, P.; Pena, A. Race-track testing of a torque vectoring algorithm on a motor-inwheel car using a model-based methodology with a HiL and multibody simulator setup. In Proceedings of the 2016 IEEE 19 th International Conference on Intelligent Transportation Systems (ITSC), Rio de Janeiro, Brazil, 1-4 November 2016; pp. 2500-2505, ISBN 978-1-5090-1889-5.5. [CrossRef]

10. Koylu, H.; Cinar, A. Experimental design of control strategy based on brake pressure changes on wet and slippery surfaces of rough road for variable damper setting during braking with activated anti-lock brake system. Proc. Inst. Mech. Eng. Part D J. Automob. Eng. 2012, 226, 1303-1324. [CrossRef]

11. Jang, J. Wheel Slip-based Road Surface Slipperiness Detection. Open Transp. J. 2020, 14, 186-193. [CrossRef]

12. Synák, F.; Kučera, M.; Skrúcaný, T. Assessing the Energy Efficiency of an Electric Car. Communications. Sci. Lett. Univ. Zilina 2021, 23, A1-A13.

13. Jilek, P.; Němec, J. System for Changing Adhesion Conditions in Experimental Road Vehicle. Int. J. Automot. Technol. 2021, 22, 779-785. [CrossRef]

14. Jilek, P.; Krmela, J.; Berg, J. Modification of the adhesive force by changing the radial reaction on vehicle wheels. Transp. Probl. 2021, 16, 179-186. [CrossRef]

15. Jilek, P.; Šefčík, I.; Verner, J. Reducing the Adhesion Force of the Wheels of the Road Vehicles; Engineering Mechanics: Svratka, Czech Republic, 2019; pp. 173-176. [CrossRef]

16. Barton, D.C.; Fieldhouse, J.D. Vehicle Structures and Materials. Barton, David C a John D Fieldhouse. In Automotive Chassis Engineering; Springer International Publishing: Cham, Switzerland, 2018; pp. 215-254. ISBN 978-3-319-72436-2. [CrossRef]

17. Marek, V.; Č upera, J. Data Mining of Vehicle Control Units. In Proceedings of International PhD Students Conference; Faculty of AgriSciences Mendel University in Brno: Brno, Czech Republic, 2016; Volume 23, pp. 944-948.

18. Ryazantsev, V.; Balabin, I.; Balsam, A. Improvement of the active safety of the vehicle for driving on the irregularities by the method of control of vertical reactions on wheels. In Proceedings of the IOP Conference Series: Materials Science and Engineering, Chennai, India, 5-9 October 2020; pp. 141-148.

19. Qureshi, K. Robust Controller Design for Active Trailer Steering Systems of Articulated Vehicles Using Multi-objective Optimization. Master's Thesis, University of Ontario Institute of Technology, Oshawa, ON, Canada, 2019.

20. Kharrazi, S.; Lidberg, M.; Fredriksson, J. A generic controller for improving lateral performance of heavy vehicle combinations. In Proceedings of the Institution of Mechanical Engineers. Part D J. Automob. Eng. 2013, 227, 619-642. [CrossRef]

21. He, Y.; Ren, J. A comparative study of car-trailer dynamics models. SAE Int. J. Passeng. Cars-Mech. Syst. 2013, 6, 177-186. [CrossRef]

22. Onat, A.; Voltr, P. Particle swarm optimization based parametrization of adhesion and creep force models for simulation and modelling of railway vehicle systems with traction. Simul. Model. Pract. Theory 2020, 99, 102026. [CrossRef]

23. Sikder, T. Design of Active Trailer Steering Systems for Long Combination Vehicles Using Robust Control Techniques. Master's thesis, University of Ontario Institute of technology, Automotive Engineering, Oshawa, ON, Canada, 2017. 
24. Caban, J.; Turski, A.; Nieoczym, A.; Tarkowski, S.; Jereb, B. Impact of specific factors on the state of the tire pressure value. Arch. Automot. Eng.-Arch. Motoryz. 2019, 85, 137-148. [CrossRef]

25. Sun, T.; He, Y. Phase-Plane Analysis for Evaluating the Lateral Stability of Articulated Vehicles. SAE Tech. Pap. 2015, 8, 63-73. [CrossRef]

26. Cheng, S.; Chen-Feng, L.; Xiang, C. A hierarchical estimation scheme of tire-force based on random-walk SCKF for vehicle dynamics control. J. Frankl. Inst. 2020, 357, 13964-13985. [CrossRef]

27. Koštial, P.; Krmela, J.; Frydrýšek, K. The Chosen Aspects of Materials and Construction Influence on the Tire Safety. In Composites and Their Properties; IntechOpen: Rijeka, Croatia, 2012; pp. 265-298. [CrossRef]

28. Stoma, M.; Dudziak, A.; Caban, J.; Droździel, P. The future of autonomous vehicles in the opinion of automotive market users. Energies 2021, 14, 4777. [CrossRef]

29. Lawoyin, S.; Fei, D.Y.; Bai, O. Accelerometer-based steering-wheel movement monitoring for drowsy-driving detection. In Proceedings of the Institution of Mechanical Engineers. Part D J. Automob. Eng. 2015, 229, 163-173. [CrossRef]

30. Kemzuraite, K. Investigation of dynamic properties of vehicle in various friction condition simulated with use of skidcar sys-tem. In The Archives of Automotive Engineering; Kemzuraite, K., Zuraulis, V., Więckowski, D., Eds.; Łukasiewicz Research Network: Warszawa, Poland, 2014; pp. 82-102.

31. Zhang, N.; Wu, J.H.; Li, T.; Zhao, Z.; Yin, G. Influence of braking on dynamic stability of car-trailer combinations. Proc. Institution Mech. Eng. Part D J. Automob. Eng. 2021, 235, 455-464. [CrossRef]

32. Tesař, M.; Jilek, P.; Pokorný, J. Experimentální měření s využitím sklopné plošiny. In XI. Mezinárodní Konference Kateder Dopravních Manipulačních, Stavebních a Zemědělských Strojů; Institute of Transport, Faculty of Mechanical Engineering, VŠB-TU Ostrava: Ostrava, Czech Republic, 2014; pp. 1-4. ISBN 978-80-248-3439-9.

33. Krmela, J.; Beneš, L.; Krmelová, V. Tire Experiments on Static Adhesor for Obtaining the Radial Stiffness Value. Period. Polytech. Transp. Eng. 2014, 42, 125-129. [CrossRef]

34. Jilek, P.; Šefčík, I.; Voltr, O.; Němec, J. The formation of car skid at a safe speed by reducing the radial response of car wheels. In Transport Means, Proceedings of the International Scientific Conference; Kaunas University of Technology: Kaunas, Lithuania, 2019; pp. 1185-1190.

35. C ČSN 69 0010-1-1 (690010). Tlakové Nádoby Stabilní. Technická Pravidla. Část 1.1: Základní část. Czech State Standard—General Provisions and Terminology. Available online: https://www.bmt.cz/data/files/legislativa/csn690010.pdf (accessed on 19 December 2021)

36. European Steel and Alloy Grades. 2020. Available online: http://www.steelnumber.com/en/steel_composition_eu.php?name_ id=331 (accessed on 19 December 2021).

37. European Steel and Alloy Grades. 2020. Available online: http://www.steelnumber.com/en/steel_composition_eu.php?name_ id=196 (accessed on 19 December 2021).

38. European Steel and Alloy Grades. 2020. Available online: http://www.steelnumber.com/en/steel_alloy_composition_eu.php? name_id=1149 (accessed on 20 December 2021). 